\title{
Análise da microestrutura e propriedade de dureza do aço SAE 1045 tratado termicamente por têmpera em diferentes meios de resfriamento
}

\author{
Analysis of the microstructure and hardness property of SAE 1045 \\ steel heat treated by quenching in different cooling media
}

\author{
1 Lucas Rafael Carneiro da Silva Ircs.carneiro@gmail.com \\ 1 Caio Carvalho Coêlho \\ 1 Miquéias Sousa Silva \\ 1 Edivaldo Feitosa Pereira Filho
}

1 Universidade Federal do Piauí, Campus Ministro Petrônio Portella, Centro de Tecnologia

\begin{abstract}
Resumo
A têmpera consiste no resfriamento brusco de uma peça aquecida visando ao aumento de dureza, no qual a constatação do grau de dureza da peça submetida ao tratamento é determinada através de ensaios de dureza, em que o método rockwell é o mais utilizado. Dependendo do meio de resfriamento usado tem-se diferentes taxas de transferência de calor com a peça a ser tratada, resultando em características distintas na dureza final da peça. Neste trabalho, foi analisada a influência da água e salmoura que atuaram como meio de resfriamento na têmpera do aço SAE 1045 através do método rockwell, e a modificação microestrutural foi sondada por microscopia óptica. Constatou-se mediante a comparação da micrografia da amostra de referência com a das amostras tratadas, que os grãos depois da têmpera se tornaram menores e com a morfologia de agulhas devido à mudança de estrutura que ocorreu no tratamento. 0 resultado obtido para a dureza da amostra resfriada em salmoura foi menor do que a da amostra resfriada em água.
\end{abstract}

\section{Palavras-chave}

Aço SAE 1045. Dureza. Rockwell. Têmpera. Tratamento térmico.

\begin{abstract}
Quenching consists of the sudden cooling of a heated part aiming to increase hardness, in which the hardness degree of the treated part is verified by hardness tests, where the rockwell method is the most used. Depending on the cooling medium used there will be different heat transfer rates with the part to be treated, resulting in distinct characteristics in the final hardness of the part. In this work, the influence of water and brine that acted as a cooling medium on SAE 1045 steel tempering was analyzed using the rockwell method, and the microstructural modification was probed by optical microscopy. It was found by comparing the micrograph of the reference sample with that of the treated samples, that the grain after quenching became smaller and the needle morphology due to the change in structure that occurred in the treatment. The result obtained for the hardness of the brine-cooled sample was lower than that of the water-cooled sample.
\end{abstract}

\section{Keywords}

SAE 1045 steel. Hardness. Rockwell. Quenching. Heat treatment.

\section{Como você deve citar?}

SILVA, Lucas Rafael Carneiro da et al. Análise da microestrutura e propriedade de dureza do aço SAE 1045 tratado termicamente por têmpera em diferentes meios de resfriamento. Cadernos UniFOA, Volta Redonda, n. 42, p. 13-21, abril, 2020. 
Análise da microestrutura e propriedade de dureza do aço SAE 1045 tratado termicamente por têmpera em diferentes meios de resfriamento.

\section{INTRODUÇÃO}

Dentre os processos de modificação de metais, os Tratamentos Térmicos possibilitam mudar as propriedades mecânicas dos aços de forma rápida e barata, além de serem o meio pelo qual são fabricadas as peças metálicas. Nesses tipos de processos, os metais e/ou ligas são submetidos a altas temperaturas e, posteriormente, resfriados, visando à modificação de suas propriedades mecânicas (GRACIOSO, 2003; CARVALHO, 2004; GHIBAN e BRAN, 2019). De acordo com Bagali et al. (2019), o aço é um material muito usado em engenharia, podendo ter microestruturas variadas conforme 0 tratamento térmico aplicado.

A Têmpera é um tratamento térmico que consiste no resfriamento brusco de uma peça aquecida, visando ao aumento de Dureza (SILVA JUNIOR et al., 2016). Na têmpera, toda a extensão da peça a ser trabalhada adquire a fase Austenita do campo Austenítico do Diagrama de Fases em aços no aquecimento, e com a redução brusca de temperatura, o material tende a adquirir a Microestrutura Martensita. As microestruturas martensíticas temperadas têm maior dureza e resistência, que podem ser desenvolvidas em um determinado aço (GRACIOSO, 2003; KRAUSS, 2014).

A transformação se dá pelo modo de resfriamento concomitante ao meio utilizado, sendo mais comum a água, mas também podem ser utilizados a salmoura, o óleo e soluções poliméricas como outras formas de resfriamento. Dependendo do meio de resfriamento utilizado, tem-se diferentes taxas de transferência de calor da peça a ser tratada, na qual, são proporcionadas características distintas na dureza final da peça (SILVA JUNIOR et al., 2016).

A verificação do grau de dureza das peças submetidas ao tratamento de têmpera é determinada através de Ensaios de Dureza (CELESTINO et al., 2007). O Método Rockwell (HRC) é o mais empregado, devido a sua simplicidade na execução, sem a necessidade de habilidades especiais do operador (CALLISTER e RETHWISCH, 2013), além da potencial vantagem de se avaliar metais com uma ampla faixa de dureza, dos mais dúcteis aos mais duros.

Neste trabalho, foi escolhido o aço SAE 1045, posto que, de acordo com Yu et al. (1988), é extensivamente empregado nas indústrias automobilística e de máquinas para manufaturar componentes sujeitos à carga cíclica, portanto, os processos de tratamento térmico normalmente são usados para aumentar a resistência e a vida útil desses componentes. Ding e Shin (2012) mencionaram que o aço 1045 tem uma relevância significativa na indústria automotiva, bem como em processos de fabricação que envolvem operações de usinagem de alta velocidade.

Perante o exposto, este trabalho objetiva analisar a influência da água e da salmoura como meio de resfriamento na dureza do aço SAE 1045 tratado termicamente por têmpera mediante o HRC, e a modificação microestrutural por meio de Microscopia Óptica (MO).

\section{MATERIAIS E MÉTODOS}

As amostras empregadas nos tratamentos térmicos foram cortadas com o auxílio de uma serra mecânica a partir de um lingote de aço SAE 1045 de seção retangular. Foi cortada uma amostra para o tratamento de têmpera em água gelada e outra em salmoura, além da amostra de referência, que não foi submetida ao tratamento. As amostras possuem as seguintes dimensões: 7,65 x 3,82 ×5,14 cm (C $x A x L$ ). Foram submetidas ao aquecimento em uma Mufla EDG 10P-S (EDG Equipamentos) com os parâmetros definidos, conforme a Tabela 1. Em relação aos meios de resfriamento, eles foram preparados de acordo com os dados da Tabela 2 . 
Tabela 1 - Parâmetros utilizados no tratamento de têmpera das amostras.

\begin{tabular}{cc}
\hline \multicolumn{2}{c}{ PARÂMETROS } \\
\hline Temperatura final de aquecimento $\left({ }^{\circ} \mathrm{C}\right)$ & 1000 \\
\hline Taxa de aquecimento $\left({ }^{\circ} \mathrm{C} \cdot \mathrm{min}^{-1}\right)$ & 10 \\
\hline Tempo de permanência na mufla $(\min )$ & 220 \\
\hline
\end{tabular}

Fonte: autores, 2019

Tabela 2 - Condições dos meios de resfriamento empregados na têmpera.

\begin{tabular}{ccc}
\hline PARÂMETROS & ÁGUA GELADA & SALMOURA \\
\hline Volume de água $(\mathrm{l})$ & 27 & 27 \\
\hline Quantidade de sal $(\mathrm{kg})$ & - & 2 \\
\hline Tempo de resfriamento $(\mathrm{min})$ & 5 & 5 \\
\hline
\end{tabular}

Fonte: autores, 2019

Após o tempo de permanência em cada meio de resfriamento, as amostras foram cortadas por serra mecânica, a fim de se analisar a modificação ocorrida internamente. Na etapa seguinte, juntamente com a amostra de referência, foram lixadas em lixas de granulações de 220 e 360 mesh. 0 polimento das amostras foi realizado em Politriz PSK 2V (SKILL-TEC), utilizando-se um aglomerante de pó de diamante. Nessa etapa, foi utilizado um pano para polimento fabricado em tecido de poliéster com a adição de abrasivos, pasta de diamante de 3 e $1 \mu \mathrm{m}$ e detergente para lubrificar e evitar que as amostras apresentassem riscos. Após, com as amostras prontas, realizou-se o Ensaio de Dureza Rockwell no equipamento ISH-BRV (INSIZE), com carga de $588 \mathrm{~N}$ e indentador cônico de diamante. As micrografias foram procedidas pelo ataque às amostras, com solução de Nital $4 \%$ ( $4 \%$ de Ácido Nítrico + 96\% de Álcool Etílico), e análise em um Microscópio Óptico modelo XJL-101 (BEL PHOTONICS), com uma ampliação de 200x. Para a captura das micrografias, foi acoplada ao microscópio uma câmera digital INSIZE modelo ISM-D300B e utilizado o Software Scopelmage 9.0.

\section{RESULTADOS E DISCUSSÃO}

\subsection{Análise da Microestrutura}

Na Figura 1, está apresentado a micrografia da amostra que não sofreu o tratamento de têmpera (referência), bem como das amostras que receberam o tratamento nos diferentes meios de resfriamento. 
Figura 1 - Micrografia óptica da amostra sem o tratamento de têmpera (a), temperada em água gelada (b) e em salmoura (c) ampliada em 200x.

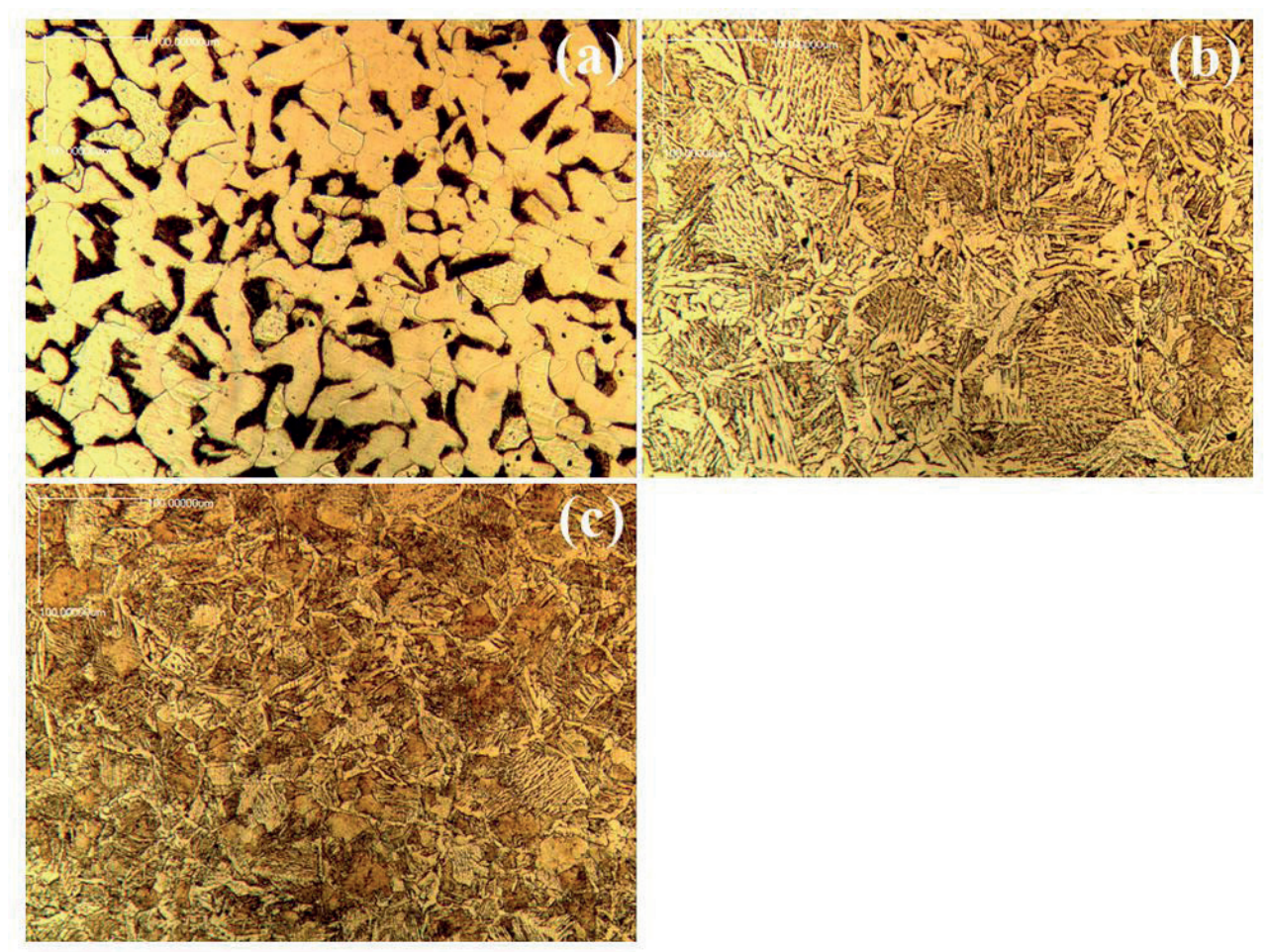

Fonte: autores, 2019.

A partir da análise da Figura 1, foi observado que a região clara da micrografia se refere à matriz ferrítica e a região escura diz respeito aos grãos de perlita (FERREIRA et al., 2004; VIDOR et al., 2014). A comparação da microestrutura da amostra de referência com a das amostras que receberam o tratamento de têmpera permitiu aferir que os grãos, após a têmpera, se tornaram menores e, com a morfologia de aguIhas, devido à mudança de estrutura cristalina que ocorreu no tratamento. A consequência dessa mudança microestrutural foi a passagem da estrutura Cúbica de Faces Centradas (CFC), característica da austenita, para a estrutura do tipo Tetragonal de Corpo Centrado (TCC), relacionada à microestrutura martensítica, provocando, consequentemente, a aparição de tensões internas na estrutura, o que aumentou o nível de dureza das amostras (MACHADO et al., 2014), como exibido na Figura 2. Liu et al. (2011) afirmaram que, apesar da martensita possuir uma morfologia de ripas, suas placas não são, em sua totalidade, integrais e são serrilhadas nas bordas. Os segmentos menores representativos dessas placas são atribuídos ao tratamento térmico. Esse tipo de morfologia também foi observado no trabalho de Nunura et al. (2015).

A microestrutura apresentada na Figura 1.b e 1.c foram semelhantes às obtidas por De Mori e Cesconeti (2018), que trataram o aço SAE 1045 por têmpera, mantendo as amostras aquecidas até 950 ${ }^{\circ} \mathrm{C}$, e utilizaram como meio de resfriamento do processo água e salmoura. Os autores concluíram que a microestrutura resultante após o tratamento de têmpera correspondeu à martensita, pois a micrografia das amostras evidenciou grãos mais alongados (agulhas), típico dessa microestrutura. A transformação dos grãos para o formato de agulha foi atribuída à rápida velocidade de resfriamento característico do tratamento de têmpera, causando a supersaturação da estrutura austenítica presente no aço aquecido nessa faixa de temperatura. Em conformidade com Akhyar e Sayuti (2015), a microestrutura final obtida para o aço, depois do tratamento a $1000^{\circ} \mathrm{C}$, foi a martensita, sendo que resultado semelhante também foi observado no trabalho de Born e Mattos (2018) ao realizarem a têmpera a $900^{\circ} \mathrm{C}$. Bhadeshia e Honeycombe (2017) afirmaram que a martensita temperada possui uma estrutura complexa. 
A respeito da microestrutura final obtida, Edmonds et al. (2006) explanaram que os tratamentos térmicos, como a têmpera, já são usados nos aços desde muito tempo, objetivando boas combinações de resistência e tenacidade com base na microestrutura martensítica. Todavia, uma desvantagem apresentada por essa microestrutura é que a propriedade de ductilidade tende a ser comprometida (LIU et al., 2011). Com o objetivo de verificar a influência da têmpera no comportamento mecânico das amostras, o ensaio de dureza foi escolhido devido à circunstância de que, no ensaio, é deixado apenas uma pequena marca (indentação) na amostra ensaiada, e essa característica torna-o relevante no controle de qualidade de um produto (AMARAL, 2016).

\subsection{Análise de Dureza}

O resultado do comportamento mecânico, especificamente, da propriedade de dureza, para a amostra de referência e para as submetidas ao processo de têmpera foi obtido através do Método Rockwell e está exibido na Figura 2.

Figura 2 - Dureza média para o aço SAE 1045: referência e meios de têmpera estudados.

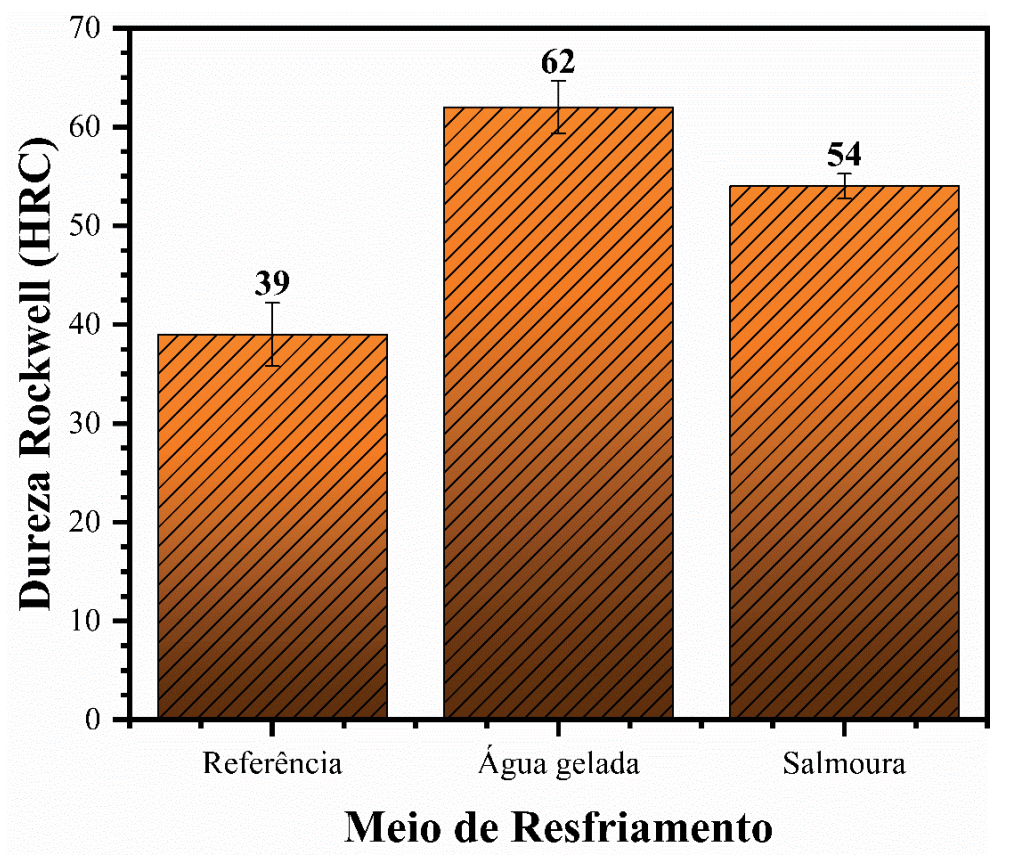

Fonte: autores, 2019

Verificou-se, através da Figura 2, que a aplicação do processo de têmpera nas amostras aumentou de modo acentuado a sua dureza, correspondendo a um aumento de $\sim 60 \%$, quando a amostra foi resfriada em água gelada, e de $\sim 40 \%$, em salmoura. Guedes e Monnerat (2017) relataram que os tratamentos térmicos influenciam os aspectos relacionados à dureza. Logo, supõe-se que o aumento de dureza sofrido pelas amostras está evidentemente associado ao meio de resfriamento utilizado no tratamento de têmpera. Saad (2012) citou que o processo de resfriamento, da temperatura de austenitização à temperatura ambiente, produz uma estrutura martensítica. Em vista disso, essa tendência que foi verificada no aumento de dureza pode estar relacionada diretamente com a estrutura do tipo TCC da martensita (TRINDADE et al., 2017). Stormvinter et al. (2011) referiram a dureza como uma consequência direta da morfologia da martensita formada. 
Observou-se que o resultado obtido para a dureza da amostra resfriada em salmoura foi menor do que a da amostra resfriada em água, no qual permitiu-se concluir que a têmpera, usando a água gelada, apresentou uma maior relevância no aumento de dureza do aço SAE 1045. Silva Junior et al. (2016) obtiveram resultados semelhantes, em que a dureza rockwell da amostra de aço SAE 1045 resfriada em água foi maior do que a da amostra resfriada em salmoura. Então, concluíram que o resfriamento que empregou a água foi o mais representativo no estudo.

No estudo de Fernandes et al. (2018), o aço SAE 1045 obteve a maior dureza, quando resfriado em água, que foi de 47,9 HRC, refletindo um aumento de $24,5 \mathrm{HRC}$ em referência ao aço que não foi temperado. Oliveira (2016) trabalhou com o SAE 1045, que foi temperado em água e revenido a $400^{\circ} \mathrm{C}$, em que foi alcançado a dureza de $56 \mathrm{HRC}$. Torres et al. (2016) também obtiveram maiores valores de dureza em relação ao aço não tratado, devido à aplicação do tratamento térmico no SAE 1045.

\section{CONCLUSÕES}

Os resultados obtidos neste trabalho permitiram concluir que, mediante a comparação da micrografia óptica da amostra de referência com a das amostras tratadas, os grãos, após a têmpera, se tornaram menores e com a morfologia de agulhas, devido à mudança de estrutura que ocorreu no tratamento, em que a consequência dessa mudança estrutural foi a passagem da estrutura CFC para a TCC. A aplicação do tratamento de têmpera aumentou de modo acentuado a dureza das amostras, correspondendo a um aumento de $\sim 60 \%$, quando foi resfriada em água gelada, e de $\sim 40 \%$, em salmoura, portanto a têmpera, empregando a água gelada, mostrou-se mais relevante no aumento de dureza do aço SAE 1045.

\section{AGRADECIMENTOS}

À Universidade Federal do Piauí (UFPI), ao Curso de Bacharelado em Engenharia de Materiais (UFPI) e ao Laboratório de Metalografia e Ensaios Mecânicos (Curso de Engenharia Mecânica - UFPI).

\section{REFERÊNCIAS}

AKHYAR, I.; SAYUTI, M. Effect of Heat Treatment on Hardness and Microstructures of AISI 1045. Advanced Materials Research, v. 1119, p. 575-579, 2015. Disponível em: https://doi.org/10.4028/www.scientific. net/AMR.1119.575. Acesso em: 05. jul. 2019.

AMARAL, Regis Fabiano. Comparativo de empenamento e microestrutural em cremalheiras de aço SAE 1045 temperadas por indução e por condução. 2016. Dissertação (Mestrado em Engenharia) - Programa de Pós-Graduação em Engenharia de Minas, Metalúrgica e de Materiais, Universidade Federal do Rio Grande do Sul, Porto Alegre, Rio Grande do Sul, 2016. Disponível em: http://hdl.handle.net/10183/153324. Acesso em: 10 nov. 2019.

BAGALI, S. V.; SIMHA, N. R. A.; SUSHANTH, M. P.; KUMAR, T. S. P.; KRISHNA, V. Estimation of Hardness During Heat Treatment of EN8 and C25 Steels. Advances in Industrial and Production Engineering, $\mathrm{p}$. 149-160, 2019. Disponível em: https://doi.org/10.1007/978-981-13-6412-9_14. Acesso em: 10 nov. 2019. 
BHADESHIA, H.; HONEYCOMBE, R. Chapter 9 - Tempering of Martensite. Steels: Microstructure and Properties, p. 237-270, 2017. Disponível em: https://doi.org/10.1016/B978-0-08-100270-4.00009-3. Acesso em: 10 nov. 2019.

BORN, R. M.; MATTOS, C. F. Comportamento do Processo de Têmpera no Aço SAE 1045 através do Resfriamento em Óleo com Viscosidades Distintas. Revista Dissertar, v. 1, n. 30, p. 207-220, 2018. Disponível em: https://doi.org/10.24119/16760867ed114237. Acesso em: 10 nov. 2019.

CALLISTER, W. D.; RETHWISCH, D. G. Ciência e engenharia de materiais: uma introdução. 8. ed. Rio de Janeiro: LTC, 2013.

CARVALHO, Antonio Rogério Torres. Estudo da Influência da Agitação e da Severidade de Têmpera do Meio de Resfriamento na Determinação de Velocidades Críticas de Têmpera. 2004. Dissertação (Mestrado em Engenharia Mecânica) - Faculdade de Engenharia Mecânica, Universidade Estadual de Campinas, São Luís, Maranhão, 2004. Disponível em: http://repositorio.unicamp.br/jspui/handle/ REPOSIP/264702. Acesso em: 05 jul. 2019.

CELESTINO, P. A. P.; FELIPE, R. C. T. S.; MACHADO, T. G. Análise comparativa entre o tratamento térmico (têmpera) e o tratamento termoquímico (cementação) realizado em aço 1040. Revista Holos, v. 3, p. 223-232, 2007. Disponível em: https://doi.org/10.15628/holos.2007.147. Acesso em: 05 jul. 2019.

DE MORI, G. N.; CESCONETI, L. B. Análise das propriedades metalográficas do aço sae 1045 nos processos térmicos de normalizaçao, revenimento e têmpera. Revista Esfera Acadêmica Tecnologia, v. 3, n. 1, p. 29-38, 2018. Disponível em: https://multivix.edu.br/wp-content/uploads/2018/10/revistaesfera-tecnologia-v03-n01-artigo03.pdf. Acesso em: 05 jul. 2019.

DING, H.; SHIN, Y. A Metallo-Thermomechanically Coupled Analysis of Orthogonal Cutting of AISI 1045 Steel. Journal of Manufacturing Science and Engineering, v. 134, n. 5, p. 051014, 2012. Disponível em: https://doi.org/10.1115/1.4007464. Acesso em: 10 nov. 2019.

EDMONDS, D. V.; HE, K.; RIZZO, F. C.; DE COOMAN, B. C.; MATLOCK, D. K.; SPEER, J. G. Quenching and partitioning martensite-A novel steel heat treatment. Materials Science and Engineering: A, v. 438-440, p. 25-34, 2006. Disponível em: https://doi.org/10.1016/j.msea.2006.02.133. Acesso em: 10 nov. 2019.

FERNANDES, K. C.; SILVA JÚNIOR, E. V. C.; SOUZA, V. B. Estudo sobre a influência dos diferentes meios resfriadores com a dureza resultante para o aço sae 1045. Revista Interdisciplinar Pensamento Científico, v. 4, n. 2, p. 112-123, 2018. Disponível em: https://doi.org/10.20951/2446-6778\%2Fv4n2a9. Acesso em: 10 nov. 2019.

FERREIRA, C. R.; ARAÚJO, F. G. S.; OLIVEIRA, C. P.; COTA, A. B. Tratamento térmico por indução eletromagnética em tubos de aço SAE 1045 para produção de hastes de sondagem geológica. Rem: Revista Escola de Minas, v. 57, n. 1, p. 23-26, 2004. Disponível em: http://dx.doi.org/10.1590/S037044672004000100005. Acesso em: 05 jul. 2019.

GHIBAN, B.; BRAN, D. T. Heat treatment behavior of alternator shafts steels. IOP Conference Series: Materials Science and Engineering, v. 572, p. 1-11, 2019. Disponível em: https://iopscience.iop.org/ article/10.1088/1757-899X/572/1/012055. Acesso em: 10 nov. 2019.

GRACIOSO, José Francisco Fadel. Efeito das condições de têmpera na microestrutura e propriedades mecânicas de um aço inoxidável martensítico fundido CA6NM. 2003. Dissertação (Mestrado em Engenharia 
Análise da microestrutura e propriedade de dureza do aço SAE 1045 tratado termicamente por têmpera em diferentes meios de resfriamento.

Mecânica) - Programa de Pós-Graduação em Engenharia Mecânica, Universidade Federal de Santa Catarina, Florianópolis, 2003. Disponível em: http://repositorio.ufsc.br/xmlui/handle/123456789/85606. Acesso em: 05 jul. 2019.

GUEDES, F. N. J.; MONNERAT, C. S. Avaliação da resistência à corrosão no aço SAE 1045 devido aos tratamentos térmicos. Revista Engenharia de Interesse Social, v. 1, n. 2, p. 1-9, 2017. Disponível em: http://200.198.28.135/index.php/reis/article/view/2412. Acesso em: 05 jul. 2019.

KRAUSS, G. 12.11 - Quench and Tempered Martensitic Steels: Microstructures and Performance. Comprehensive Materials Processing, v. 12, p. 363-378, 2014. Disponível em: https://doi.org/10.1016/ B978-0-08-096532-1.01212-7. Acesso em: 10 nov. 2019.

LIU, H.; JIN, X.; DONG, H.; SHI, J. Martensitic microstructural transformations from the hot stamping, quenching and partitioning process. Materials Characterization, v. 62, n. 2, p. 223-227, 2011. Disponível em: https://doi.org/10.1016/j.matchar.2010.12.003. Acesso em: 10 nov. 2019.

MACHADO, N. T. B.; DOS PASSOS, M. L. M.; RECCO, A. A. C.; RIANI, J. C. Análise das propriedades mecânicas do aço 1045 nitretado a plasma: com e sem tratamento de revenimento. $21^{\circ}$ Congresso Brasileiro de Engenharia e Ciência dos Materiais, p. 5426-5433, 2014. Disponível em: http://www. metallum.com.br/21cbecimat/CD/PDF/305-029.pdf. Acesso em: 05 jul. 2019.

NUNURA, C. R. N.; SANTOS, C. A.; SPIM, J. A. Numerical - Experimental correlation of microstructures, cooling rates and mechanical properties of AISI 1045 steel during the Jominy end-quench test. Materials \& Design, v. 76, p. 230-243, 2015. Disponível em: https://doi.org/10.1016/j.matdes.2015.03.031. Acesso em: 10 nov. 2019.

OLIVEIRA, Loani Bassani. Influência do cálcio na corrosão do aço SAE 1045 temperado e revenido em soluções ricas em $\mathrm{CO}_{2}$ em alta pressão e alta temperatura. 2016. Dissertação (Mestrado em Engenharia e Tecnologia de Materiais) - Programa de Pós-Graduação em Engenharia e Tecnologia de Materiais, Pontifícia Universidade Católica do Rio Grande do Sul, Porto Alegre, Rio Grande do Sul, 2016. Disponível em: http://tede2.pucrs.br/tede2/handle/tede/6878. Acesso em: 10 nov. 2019.

SAAD, Abdullah Aziz. Cyclic plasticity and creep of power plant materials. 2012. PhD thesis, University of Nottingham, 2012. Disponível em: http://eprints.nottingham.ac.uk/id/eprint/12538. Acesso em: 10 nov. 2019.

SILVA JUNIOR, R. P.; BIAZOTTO, G. C.; VATAVUK, J.; CALICCHIO, L. Têmpera de aço SAE 1045 utilizando diferentes meios de resfriamento. $71^{\circ}$ Congresso Anual da ABM, p. 1405-1412, 2016. Disponível em: https://abmproceedings.com.br/ptbr/article/download-pdf/tempera-de-aco-sae-1045-utilizandodiferentes-meios-de-resfriamento. Acesso em: 05 jul. 2019.

STORMVINTER, A.; BORGENSTAM, A.; HEDSTRÖM, P. Investigation of Lath and Plate Martensite in a Carbon Steel. Solid State Phenomena, v. 172-174, p. 61-66, 2011. Disponível em: https://doi.org/10.4028/ www.scientific.net/SSP.172-174.61. Acesso em: 10 nov. 2019.

TORRES, J. R. G.; AVILA, C. A. B.; HERNANDEZ, M. E.; MOLANO, H. F. R. Influencia en las propiedades mecánicas del acero AISI-SAE 1045 tratado térmicamente con temple a temperatura intercrítica y revenido. Avances: Investigacion en Ingeniería, v. 13, n. 1, p. 13, 2016. Disponível em: https://doi. org/10.18041/1794-4953/avances.2.257. Acesso em: 10 nov. 2019. 
TRINDADE, D. R.; SANTOS, P. H. Q.; RODRIGUES, R. F. N.; DIAS, M. J.; FARIA, E. C. M.; CASTRO, A. N. Estudo e Avaliação do Tempo de Permanência a Temperatura no Tratamento Térmico de Têmpera do Aço SAE 1045. Revista Processos Químicos, v. 11, n. 21, p. 67-76, 2017. Disponível em: https://doi. org/10.19142/rpq.v11i21.395. Acesso em: 10 nov. 2019.

VIDOR, G. F.; LOPES, N. F.; MARCOLINO, J. B.; MORAES, M. K.; COSTA, E. M. Influência da microestrutura do aço ao carbono SAE 1045 na corrosão por $\mathrm{CO}_{2}$ a alta pressão e a alta temperatura nos estados: encruado, recozido e temperado e revenido. $21^{\circ}$ Congresso Brasileiro de Engenharia e Ciência dos Materiais, p. 5699-5706, 2014. Disponível em: http://www.metallum.com.br/21 cbecimat/CD/PDF/306006.pdf. Acesso em: 05 jul. 2019.

YU, M. T.; DUQUESNAY, D. L.; TOPPER, T. H. Notch fatigue behaviour of SAE1045 steel. International Journal of Fatigue, v. 10, n. 2, p. 109-116, 1988. Disponível em: https://doi.org/10.1016/0142-1123(88)90038-2. Acesso em: 10 nov. 2019. 